\title{
First results of fair-weather atmospheric electricity measurements in Northeast India
}

\author{
A Guha ${ }^{1, *}, \mathrm{~B} \mathrm{~K} \mathrm{DE}^{1}$, S Gurubaran ${ }^{2}$, S S De ${ }^{3}$ and K Jeeva ${ }^{2}$ \\ ${ }^{1}$ Department of Physics, Tripura University, Suryamaninagar, Tripura (West) 799 130, India. \\ ${ }^{2}$ Equatorial Geophysical Research Laboratory, Indian Institute of Geomagnetism, Krishnapuram, \\ Tirunelveli 627 011, India. \\ ${ }^{3}$ Centre of Advanced Study in Radiophysics and Electronics 1, Girish Vidyaratna Lane, \\ University of Calcutta, Kolkata 700 009, India. \\ *e-mail: anirban1001@yahoo.com
}

\begin{abstract}
During the month of March 2006, a short campaign was conducted to measure fair-weather atmospheric electricity parameters in Tripura, Northeast India $\left(23.50^{\circ} \mathrm{N}, 91.25^{\circ} \mathrm{E}\right)$. The campaign was the first of its kind in this region of the globe. The main objective of the campaign was to characterize the diurnal variation of three parameters namely vertical potential gradient $(E)$, vertical air-earth current density $\left(J_{z}\right)$ and atmospheric electrical conductivity $(\sigma)$ in fair-weather conditions. The diurnal variation of $E$ and $J_{z}$ over sixteen fair-weather days shows two distinct maxima around $14 \mathrm{UT}$ and $20 \mathrm{UT}$ and a minimum around $03 \mathrm{UT}$. The average vertical potential gradient is found to be $108 \mathrm{~V} \cdot \mathrm{m}^{-1}$ and air-earth current density $1.85 \mathrm{pA} \cdot \mathrm{m}^{-2}$. The average bipolar atmospheric electrical conductivity at the ground level is found to be $19.6 \mathrm{fS} \cdot \mathrm{m}^{-1}$. An excellent positive correlation between $E$ and $J_{z}$ is found, with a correlation coefficient of 0.96 . A comparative study with Carnegie universal variation shows $70 \%$ correlation with observed variation of vertical potential gradient during the period of the campaign. The results are discussed in view of difficulty as well as possibility of getting global signatures in atmospheric electricity measurements made from tropical land stations.
\end{abstract}

\section{Introduction}

The electrical properties of Earth's atmosphere have been continually investigated since the late eighteenth century, due to its relevance with local climate system and the possible connection with global solar terrestrial activities. The discovery of the highly conducting ionosphere in the 1920s initiated long-range propagation of radio waves and was important for the evolution of the concept of the Global Electric Circuit (GEC). The ionosphere, with its large electrical conductivity compared to the neutral atmosphere, provided a means of closing the global circuit. The electric currents and fields in the fair-weather atmosphere are driven by the combined action of the ionospheric and magnetospheric dynamo systems as well as by current generators at the planetary boundary layer (Markson 2007).

One of the milestones in the study of the GEC through atmospheric electricity was several Carnegie voyages around the year 1920 which revealed the universal variation of the fair-weather vertical potential gradient and also its correlation with the occurrence of thunderstorms at different parts of the world (Wilson 1920; Simpson 1929; Parkinson and Torrenson 1931). It was pointed out that the average diurnal variations of the vertical potential gradient over long periods at ground level in fair-weather conditions match closely to the global diurnal variation in thunderstorm activities (Whipple and Scrase 1936). Several other

Keywords. Global electric circuit; atmospheric vertical potential gradient; air-earth current density; atmospheric electrical conductivity. 
independent measurements supported the findings which are reviewed by several workers (Israel 1973a, 1973b; Siingh et al 2007).

The study of atmospheric electricity has been an important tool to investigate the global thunderstorm activity as well as solar terrestrial relationship with Earth's atmosphere. Recent researches show major concerns like climate change and global warming issues may be well understood (Bering III 1995; Williams 2007) investigating the cross-correlation among these fundamental parameters. The developments and recent trends in this area are extensively studied and reviewed by several research workers (Roble and Tzur 1986; Bering III et al 1998; Rycroft et al 2000; Tinsley 2000; Singh et al 2004; Harrison 2005; Siingh et al 2005; Williams 2005; Rycroft 2006). The contribution from electrified shower clouds on GEC is one of the current burning topics of investigation (Williams 2009). All the works emphasize the need for more elaborate and accurate measurements of different atmospheric electricity parameters to have a comprehensive understanding about the interrelationship between climate change, thunderstorm activity, electrified shower clouds and solar variations.

Ground based fair-weather measurements in pollution free regions have often proved as the most frequently used (Anderson 1967; Leblanc et al 2008) and reliable technique to study atmospheric electricity, be it global, regional or local. In this paper, our aim is to report the first measurements of fair-weather atmospheric electricity at a tropical land station in Northeast India. The results are discussed briefly in connection with its dependence on local factors as well as in view of its correlation with the Carnegie diurnal variation of ionospheric potential.

\section{Short description of the experimental site}

The campaign was conducted inside Tripura University campus $\left(23.50^{\circ} \mathrm{N}, 91.25^{\circ} \mathrm{E}\right)$, located around $43 \mathrm{~m}$ above the mean sea level. The distance to the Great Himalayas is around $350 \mathrm{~km}$ and the Bay of Bengal is around $150 \mathrm{~km}$ from the site. The nearest city Agartala, the capital of the state Tripura, is $10 \mathrm{~km}$ away from the site. The experimental site is an open field around 1.5 acres in area. The site is relatively less polluted compared to urban locations due to the absence of nearby industries. The site receives severe thunderstorms locally known as 'Nor-Wester' in the month of April-May and heavy monsoon rain from June to August every year. The site is also hit by heavy rain from depressions created in the Bay of Bengal several times in a year.

\section{Experimental setup}

An air-earth current measurement unit, a field-mill and a Gerdien condenser were operated simultaneously to measure different atmospheric electricity parameters during the campaign. The instruments were designed to measure fair-weather vertical airearth current density $\left(J_{z}\right)$, vertical potential gradient $(E)$ and atmospheric electrical conductivity $(\sigma)$ of air at ground level, respectively. The instruments and corresponding high impedance electrometers were designed by Equatorial Geophysical Research Laboratory (EGRL), Tirunelveli, India. Military grade components were used in all electronic circuits to maintain their characteristics at different temperatures. The electrometer for air-earth current measurement was originally calibrated at National Physical Laboratory, New Delhi, India, electrometer for Gerdien condenser was originally calibrated at Equatorial Geophysical Research Laboratory, Tirunelveli, India and the field-mill was originally calibrated at Indian Institute of Tropical Meteorology, Pune, India.

The vertical air-earth current was measured with the help of a horizontal long wire antenna of $33 \mathrm{~m}$ in length and $2 \mathrm{~mm}$ in diameter at a height of $1 \mathrm{~m}$ from the ground. The antenna was made using bare pre-stretched copper wire. The wire was suspended in air with the help of two metal masts and the current flowing through the wire was passed through the electrometer located at one end of the wire antenna. The antenna wire was separated from the metallic masts using teflon insulators. The electrometer was calibrated to produce $1 \mathrm{~V}$ output for a current of $1 \mathrm{pA}$. The resolution of the electrometer was $0.05 \mathrm{pA}$.

The atmospheric air-earth current density was calculated using the method of area averaging (Tammet et al 1996). The horizontal long wire antenna, if placed in the atmosphere closely follows the electrical current variations of the atmosphere by collecting incoming charges from the atmosphere after the initial net charge on the antenna leaks off. When the antenna is connected to ground through a resistor, it picks up a certain amount of current proportional to the air-earth current. The method also greatly reduces the fluctuations caused by local disturbances. The average capacitance $C$ between the wire and Earth was measured and the effective area $A$ was calculated from the formula $A=h C / \varepsilon$ where $h=1 \mathrm{~m}$ and $\varepsilon$ is the dielectric constant of the air. The effective area was calculated to be $90.48 \mathrm{~m}^{2}$. The total current passing through the antenna was divided by the effective area to get the current density.

The atmospheric vertical potential gradient was measured with a field-mill which worked on the principle of bound charge. The field-mill was 
installed in a pit in such a way that the sensor plates lie exactly parallel to the surrounding ground. This was to ensure that the presence of the field-mill had no effect on the intensity of electric field near the measuring instrument in the open atmosphere. On site calibration was performed to validate the data. The field-mill was capable of detecting a field between $-250 \mathrm{~V} \cdot \mathrm{m}^{-1}$ and $250 \mathrm{~V} \cdot \mathrm{m}^{-1}$ with a resolution of $0.25 \mathrm{~V} \cdot \mathrm{m}^{-1}$.

The positive electrical air-conductivity at one foot above the ground level was measured using a Gerdien condenser. The critical mobility of the Gerdien condenser was calculated as $2.91 \times 10^{-4} \mathrm{~cm}^{2} \cdot \mathrm{V}^{-1} \cdot \mathrm{s}^{-1}$, i.e., the condenser could detect ions with minimum mobility of $2.91 \times 10^{-4} \mathrm{~cm}^{2} \cdot \mathrm{V}^{-1} \cdot \mathrm{s}^{-1}$. So the condenser was able to measure the conductivity for a wide range of charged particles beginning from small ions from a few nanometers to intermediate and large ions having a maximum radius up to $50 \mathrm{~nm}$ (Tammet 1995).

The surrounding ground for all the instruments was completely freed from grass and other vegetation and levelled to reduce or remove the effects of point discharge currents. A proper earthing arrangement was made in the vicinity of the field instruments to provide common earthing to all the instruments. Regular cleaning of instruments using isopropyl alcohol was made to ensure the elimination of dust particles from the surface of the field instruments. Regular checking of zero shifting for all the electrometers was also done using standard procedures. All the data were recorded round the clock inside a laboratory $50 \mathrm{~m}$ away from the experimental field. The data were taken from the field using shielded RG58 coaxial cable. A Pentium-IV $3 \mathrm{GHz}$ computer equipped with a 24-bit PCI interface bipolar data acquisition card was used to record the data with an interval of one second.

\section{Selection of fair-weather data}

The campaign continued for the entire month of March 2006. Out of whole month's data, only sixteen days' data were selected as fair-weather data and included for analysis in the present work. The data were selected for the days when no precipitation and local thunderstorm activity was present, the sky was clear with bright sunshine, high altitude cloud occupying less than one octet of the whole sky and a gentle breeze having speed less than $3 \mathrm{~m} \cdot \mathrm{s}^{-1}$. If any one of the above conditions did not satisfy for any time during the whole period of any day, the entire data of that day was excluded from the analysis. During the period of selected sixteen days' data, no geomagnetic storm occurred and the average $K_{p}$ and $A_{p}$ indices were 1.5 and 8 , respectively.

\section{Observational results}

The diurnal variation of fair-weather vertical airearth current density $\left(J_{z}\right)$, vertical potential gradient $(E)$ and atmospheric positive conductivity $\left(\sigma_{+}\right)$ averaged over sixteen days is shown in figure 1 . The mean value of $J_{z}$ is $1.85 \mathrm{pA} \cdot \mathrm{m}^{-2}$ with a standard deviation of $0.23 \mathrm{pA} \cdot \mathrm{m}^{-2}$. For $E$, the mean value is $108 \mathrm{~V} \cdot \mathrm{m}^{-1}$ with a standard deviation of $8.25 \mathrm{~V} \cdot \mathrm{m}^{-1}$. Two distinct maxima and one minimum are found around 14 UT, $20 \mathrm{UT}$ and $3 \mathrm{UT}$, respectively in both $J_{z}$ and $E$. The ratio of maximum to minimum values for $J_{z}$ and $E$ are 1.77 and 1.37 , respectively. The mean value of $\sigma_{+}$is $9.8 \mathrm{fS} \cdot \mathrm{m}^{-1}$ with a standard deviation of $0.1 \mathrm{fS} \cdot \mathrm{m}^{-1}$. The data was originally taken at a rate of one per second. At this sampling data rate, all the three parameters showed fluctuations about some mean value during the whole observational period. The fluctuations were higher during local sunrise and sunset times compared to other timings. In order to reduce the fluctuation, we took a running average of the data at five-minute interval. Then we took the average of all fair-weather day data according to our selection criteria. The average daily dynamic ranges of vertical potential gradient, air-earth current and positive air-ion conductivity are $35 \mathrm{~V} \cdot \mathrm{m}^{-1}$, $1 \mathrm{pA} \cdot \mathrm{m}^{-2}$ and $0.2 \mathrm{fS} \cdot \mathrm{m}^{-1}$, respectively.

The total conductivity (positive and negative) of air $\sigma_{t}$ is related to the ion number concentration $n$ and their motilities $\mu$ as $\sigma_{t}=e \int n d \mu$. The electrical conductivity of air is mainly controlled by small ions having average mobility in the range $1.3-1.6 \mathrm{~cm}^{2} \mathrm{~V}^{-1} \mathrm{~s}^{-1}$ (Hõrrak et al 1999). So assuming that all small ions have the same mobility, the expression of total air-ion conductivity can be approximated as $\sigma_{t}=n e \mu$ for diurnal averaging purpose (Harrison 1992). Also, considering charge neutrality of the atmosphere near ground, the total atmospheric conductivity $\left(\sigma_{t}\right)$ is calculated as $19.6 \mathrm{fS} \cdot \mathrm{m}^{-1}$ from the value of positive conductivity. As the mobility of the small positive and negative ions are almost the same near the Earth's surface, both positive and negative ions move under the influence of atmospheric electric field. As a result, the current density becomes dependent on both ions (Rycroft et al 2008).

Figures 2-4 present the histograms for the averaged $J_{z}, E$ and $\sigma_{t}$ over sixteen fair-weather days having data resolution of one second. For $J_{z}$, $64 \%$ data lie within $10 \%$ of the mean value of $1.85 \mathrm{pA} \cdot \mathrm{m}^{-2}$. Similarly, for $E, 80 \%$ data lie within $10 \%$ of the mean value of $108 \mathrm{~V} \cdot \mathrm{m}^{-1}$. The conductivity histogram shows two maxima, one centered 

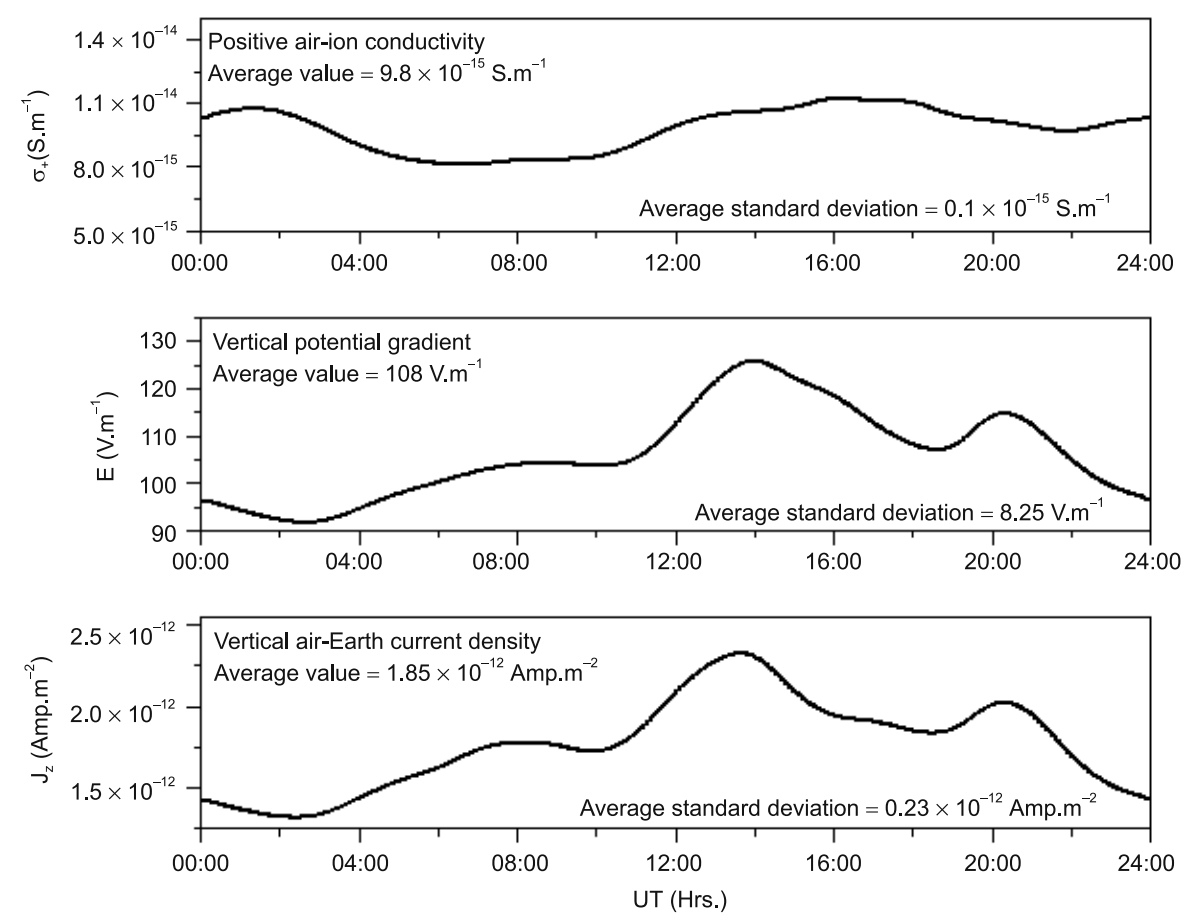

Figure 1. Diurnal variation of atmospheric vertical air-earth current density $\left(J_{z}\right)$, vertical potential gradient $(E)$ and positive air-ion conductivity $\left(\sigma_{+}\right)$near ground for sixteen days in Tripura, Northeast India.

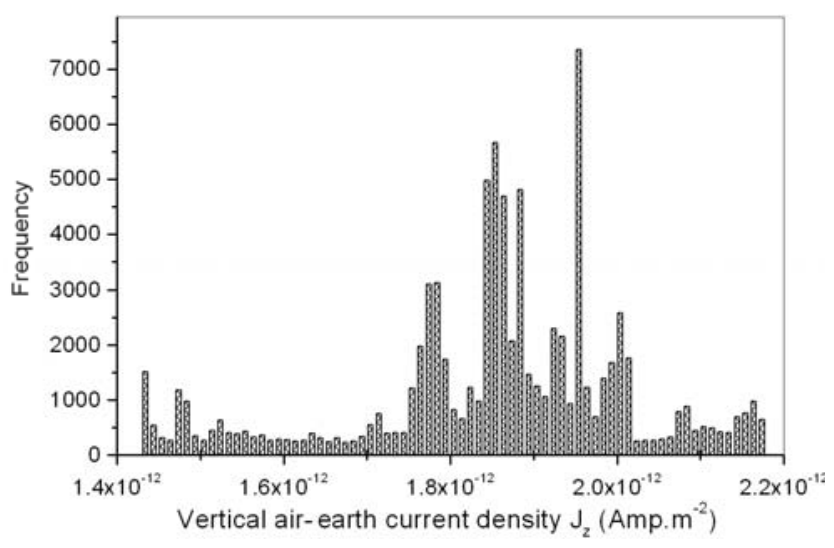

Figure 2. Histogram of vertical air-earth current density $\left(J_{z}\right)$ for sixteen fair-weather days.

about the mean value, i.e., $9.8 \mathrm{fS} \cdot \mathrm{m}^{-1}$ and another about $8.2 \mathrm{fS} \cdot \mathrm{m}^{-1}$. About $55 \%$ counts lie between $10 \%$ of the mean value of $9.8 \mathrm{fS} \cdot \mathrm{m}^{-1}$.

An excellent positive correlation of $96 \%$ is found between $J_{z}$ and $E$. The correlation plot is depicted in figure 5. The high correlation verifies the applicability of Ohm's law in our measurements which is one of the necessary conditions for fair-weather atmospheric electricity measurements. The atmospheric bipolar total conductivity $\left(\sigma_{t}\right)$ calculated from the ratio of $J_{z} / E$ from figure 5 is found to be $17 \mathrm{fS} \cdot \mathrm{m}^{-1}$. It is to be noted that the $\sigma_{t}$ found from direct measurement is $19.6 \mathrm{fS} \cdot \mathrm{m}^{-1}$, is very close to the value calculated from Ohm's law.

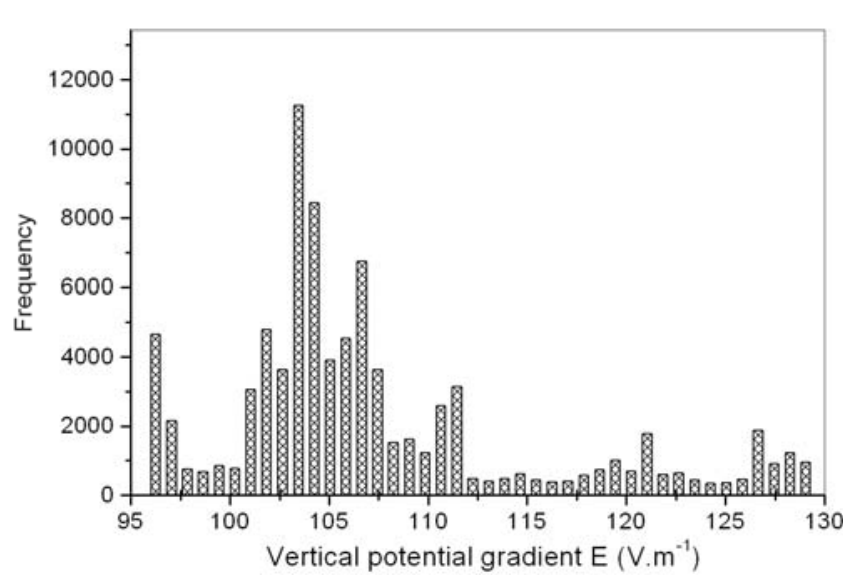

Figure 3. Histogram of vertical potential gradient $(E)$ for sixteen fair-weather days.

We compared our results with Carnegie diurnal variation which is regarded as the reference for any atmospheric electricity measurements. The plot for both vertical potential gradients is shown in figure 6 . The average value for our measurement is $108 \mathrm{~V} \cdot \mathrm{m}^{-1}$ compared to $127 \mathrm{~V} \cdot \mathrm{m}^{-1}$ in case of Carnegie variation. The diurnal variation at our location shows a resemblance with Carnegie variation except around 14 UT when a strong maximum exists in our result. The comparison of both potential gradients provides a correlation coefficient of +0.7 and the correlation plot is shown in figure 7 . 


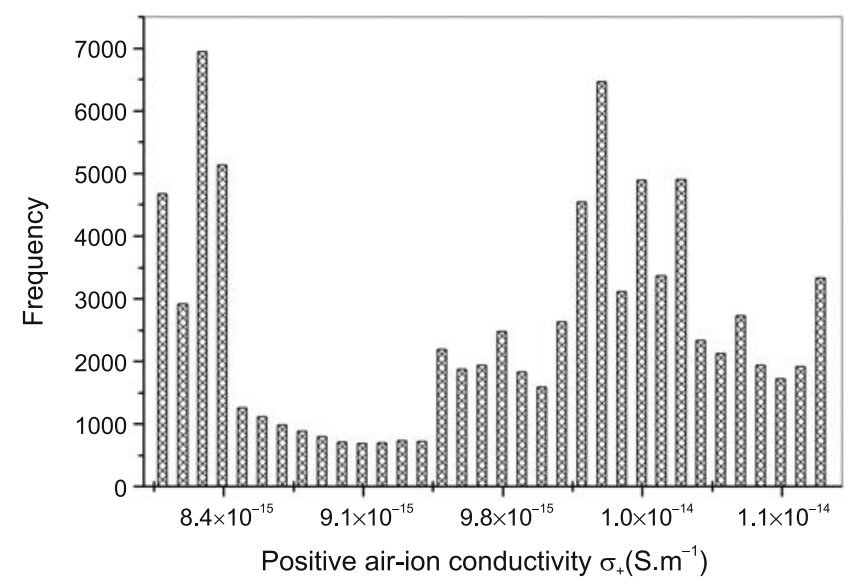

Figure 4. Histogram of positive air-ion conductivity $\left(\sigma_{+}\right)$ for sixteen fair-weather days.

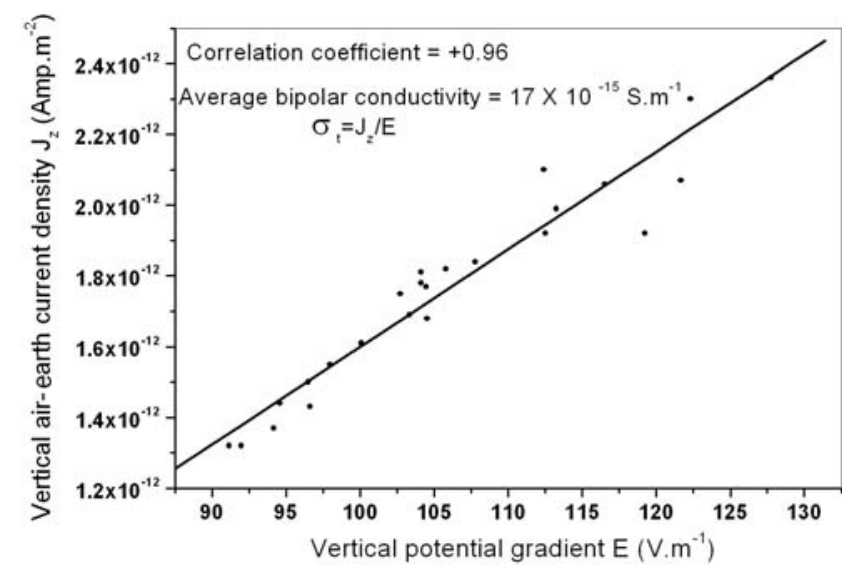

Figure 5. Correlation plot between vertical potential gradient $(E)$ and vertical air-earth current density $\left(J_{z}\right)$.

\section{Discussions}

An excellent review is done by Williams (2009) about three electrical parameters measured by various workers at different locations over a vast span of time. The values presented there are well comparable to the values of the three parameters we have measured. One of the most challenging tasks in the surface measurement of atmospheric electric parameters is finding the signatures of global thunderstorm activity. The global signature is often totally masked by disturbed weather conditions, local changes due to aerosol pollution, space charge, radioactive pollution, etc. The processes in planetary boundary layer play a crucial role in the diurnal variation of atmospheric parameters. The most suitable parameter for monitoring the global circuit is ionospheric potential $\left(V_{I}\right)$ and after that in order of merit, vertical air-earth current density $\left(J_{z}\right)$ and vertical potential gradient $(E)$ comes into picture (Markson 2007). $J_{z}$ is dependent on $V_{I}$ and columnar resistance of the atmosphere $\left(R_{c}\right)$ as
$J_{z}=V_{I} /\left(A_{\text {eff }} R_{c}\right)$ whereas $E$ is related with $V_{I}, R_{c}$ and atmospheric conductivity $(\sigma)$ near Earth's surface as $E=V_{I} /\left(\sigma A_{\text {eff }} R_{c}\right)$, ' $A_{\text {eff }}$ ' being the effective area through which the total current passes. It can be readily observed that $E$ is highly dependent on local variation of atmospheric conductivity compared to $J_{z}$. This is the reason why the variation of $J_{z}$ is often treated as the representative of ionospheric potential over $E$. Nevertheless, there are evidences of global signatures in measurements of vertical potential gradient in fair-weather in remote locations, far from sources of pollution, and during fair-weather conditions (Frank-Kamenetsky et al 2001; Reddell et al 2004; Burns et al 2005; Panneerselvam et al 2007).

In fair-weather condition, electrical conductivity of the atmosphere near ground is governed by small ions having sizes of few nanometers and indicates the level of atmospheric pollution and aerosol concentration (Cobb and Wells 1970; Kamra et al 2001; Deshpande and Kamra 2002; Siingh et al 2005). Immediately above the continental surface, the total conductivity (the sum of the positive and negative ion conductivity) ranges typically in between $2 \mathrm{fS} \cdot \mathrm{m}^{-1}$ for highly polluted regions to $20 \mathrm{fS} \cdot \mathrm{m}^{-1}$ for relatively clean regions (Chalmers 1967) and up to $40 \mathrm{fS} \cdot \mathrm{m}^{-1}$ in clean marine air (Cobb and Wells 1970). Table 1 shows the values of total atmospheric conductivity near Earth's surface for some atmospheric electricity measurements along with our data. The average atmospheric total electrical conductivity at our station is $19.6 \mathrm{fS} \cdot \mathrm{m}^{-1}$. The high correlation (96\%) between $J_{z}$ and $E$, validation of Ohm's law along with an indication of clean atmosphere from the value of electrical conductivity gives us the confidence to look for regional as well as global signatures in our results.

According to the standard model, there are three major thunderstorm occurring centers in the entire world namely Asia-Australia region, African region and South American region (Bering III et al 1998) which peaks around $09 \mathrm{UT}, 14 \mathrm{UT}$ and 19 UT, respectively. The unitary diurnal variation of vertical potential gradient shows a maximum around 19-20 UT and a minimum around 3-4 UT if the data is averaged for long time span. Data averaging of 130 fair-weather days spread over several years was required for the unitary diurnal variation to emerge in the Carnegie curve (Wilson 1920). Data of shorter span from tropical regions show considerable deviation from the unitary one (Kamra et al 1994) due to several factors like temporal and spatial distribution of thunderstorm all over the globe (Dolezalek 1972). Results from 20 fair-weather days from Indian station at Maitri, Antarctica (Deshpande and Kamra 2001) also exhibit a significant deviation from unitary 

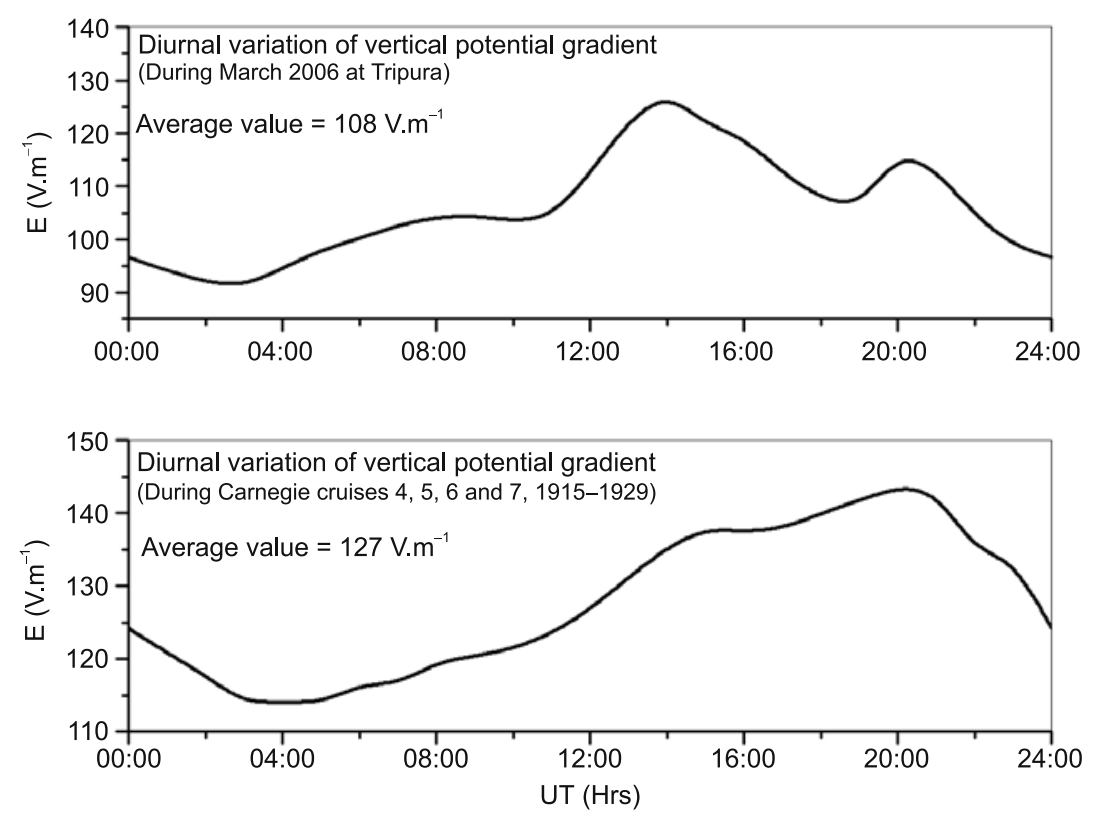

Figure 6. Comparison between diurnal variation of vertical potential gradient $(E)$ at Tripura and Carnegie voyages.

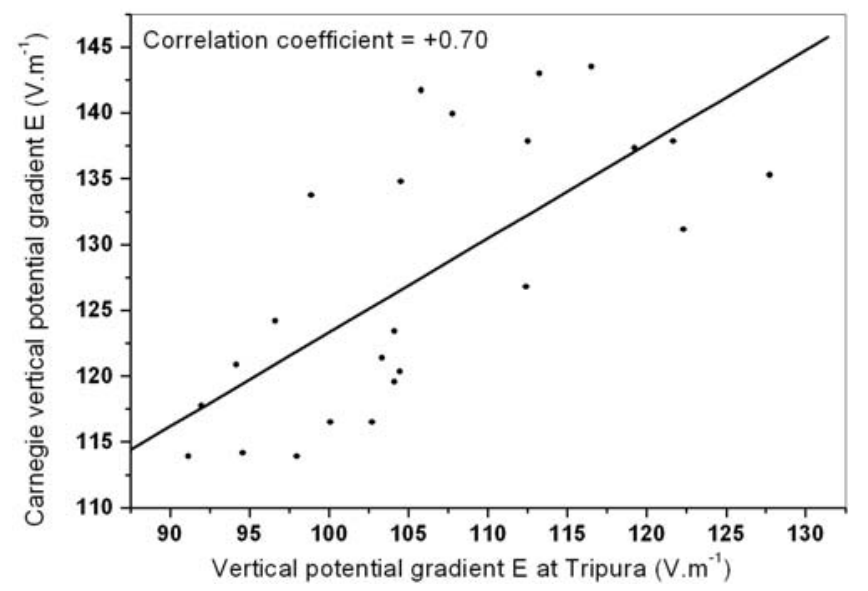

Figure 7. Correlation plot between vertical potential gradient $(E)$ at Tripura and Carnegie voyages.

variation showing two maxima around $13 \mathrm{UT}$ and 19 UT and a minimum at 01 UT. Anderson (1969) explained the deviation of air-earth current density measured by them as a result of imperfect propagation of effects of thunderstorms from one side of the Earth to the other side. Our data show two distinct maxima around $14 \mathrm{UT}$ and $20 \mathrm{UT}$ and a minimum around $3 \mathrm{UT}$. The question arises whether the variation observed from our station represents variation of global ionospheric potential, a contribution of regional thunderstorm activity or it is totally controlled by local aerosol and space charge variations in planetary boundary layer.

It is worth mentioning that there are several fairweather results from pollution free regions which indicate a deviation from unitary diurnal variation especially when the data are averaged over short
Table 1. Atmospheric electrical conductivity values near Earth's surface measured by several workers.

\begin{tabular}{|c|c|c|}
\hline Location & Reference & $\begin{array}{l}\text { Conductivity } \\
\left(\mathrm{fS} \cdot \mathrm{m}^{-1}\right)\end{array}$ \\
\hline \multirow[t]{3}{*}{ Oceans } & $\begin{array}{l}\text { Cobb and Wells } \\
(1970)\end{array}$ & 30 \\
\hline & $\begin{array}{l}\text { Swann (1915); } \\
\text { Ault and } \\
\text { Mauchly (1925) }\end{array}$ & 35 \\
\hline & $\begin{array}{l}\text { Torreson et al } \\
\quad(1946)\end{array}$ & \\
\hline \multicolumn{3}{|l|}{ Sea } \\
\hline $\begin{array}{l}\text { Bay of Bengal } \\
\text { (within } 1500 \mathrm{~km} \\
\text { from coastline) }\end{array}$ & $\begin{array}{l}\text { Kamra and } \\
\text { Deshpande } \\
(1995)\end{array}$ & 9 \\
\hline \multicolumn{3}{|l|}{ Land } \\
\hline Peebles, Scotland & Harrison (2007) & 13 \\
\hline Eskdalemuir, Scotland & Harrison (2007) & 9.8 \\
\hline Edinburgh, Scotland & Harrison (2007) & 5.1 \\
\hline Kew, England & Harrison (2007) & 3.8 \\
\hline Our measurements & & 19.6 \\
\hline
\end{tabular}

period (Kasemir 1972). Even a closer look at the seasonal variation of Carnegie data reveals that during the months of March-April-May, the data of 46 fair-weather days exhibit a unitary diurnal variation having a maximum around $15 \mathrm{UT}$ instead around 19-20 UT (Rycroft 2008). Several works point to the role of electrified shower clouds and its contribution in comparison to global thunderstorm activity and lightning activity in modulating GEC (Williams and Satori 2004; Williams 2009). It was Wilson (1920) who first argued that electrified shower clouds were equally important along 
with thunderstorm activity as one of the sources of GEC. It is to be noted that spatial and temporal distribution of electrified shower cloud could play a vital role in the determination of global ionospheric potential over periods of time. The current knowledge of monsoon shower clouds in modulating ionospheric potential is also not wellunderstood.

\section{Concluding remarks}

The diurnal variation of $J_{z}$ and $E$ at our station correlates $70 \%$ to Carnegie unitary diurnal variation but it must be emphasized that we averaged only sixteen fair-weather days' data within a single month compared to 130 days' data spread over several years. It requires collection of more data and further investigation to conclude whether fair-weather surface measurements of atmospheric parameters especially from tropical stations really point to a unitary diurnal variation of ionospheric potential especially over shorter time span. In view of the short duration of our observation period, we would like to only report our observation in this present paper. Based on the observation of fair-weather atmospheric electricity parameters in the Bay of Bengal, Indian Ocean and Arabian Sea, Kamra et al (1994) questioned the unitary diurnal variation and argued whether their observation reflects any modulation of GEC at tropical latitudes by another agent besides thunderstorm activity. Deshpande and Kamra (2001) explained the deviation in terms of the seasonal variation of the longitudinal distribution of thunderstorm activity. We believe more fairweather experiments at tropical latitudes spanned over different seasons would certainly answer these questions and enrich the knowledge of fundamental understandings in the field of atmospheric electricity research.

\section{Acknowledgements}

The campaign was funded via a scientific project under Indian Space Research Organization (ISRO), through S K Mitra Centre for Research in Space Environment, University of Calcutta, India. We are greatly thankful to the research scholars of the Department of Physics, Tripura University for their active support during the campaign.

\section{References}

Anderson R V 1967 Measurement of worldwide diurnal atmospheric electricity variations; Mon. Wea. Rev. 95(12) 899-904.
Anderson R V 1969 Universal diurnal variation in air-earth current density; J. Geophys. Res. 74 1697-1700.

Ault J P and Mauchly S J 1925 Atmospheric electricity results obtained aboard the 'Carnegie'; Publ. Rep. 127 Carnegie Inst., Washington DC., 197-286.

Bering III E A 1995 The global circuit: Global thermometer, weather by product or climate modulator?; Rev. Geophys. 33 845-862.

Bering III E A, Few A A and Benbrook J R 1998 The global electric circuit; Phys. Today 51 24-30.

Burns G B, Frank-Kamenetsky A V, Troschichev O A, Bering E A and Reddell B D 2005 Interannual consistency of bi-monthly differences in annual variations of the ground-level, vertical electric field; J. Geophys. Res. 110 D10106, doi:10.1029/2004JD005469.

Chalmers J A 1967 Atmospheric electricity, 2nd edn, Pergamon Press.

Cobb W E and Wells H J 1970 The electrical conductivity of oceanic air and its correlation to global atmospheric pollution; J. Atmos. Sci. 27 814-819.

Deshpande C G and Kamra A K 2001 Diurnal variations of the atmospheric electric field and conductivity at Maitri, Antarctica; J. Geophys. Res. 106(D13) 14,207-14,218.

Deshpande C G and Kamra A K 2002 Atmospheric electric conductivity measurements over the Indian Ocean during the Indian Antarctic Expedition in 1996-1997; J. Geophys. Res. 107(D21) 4598, doi:10.1029/2002JD002118.

Dolezalek H 1972 Discussion of the fundamental problem of atmospheric electricity; Pure Appl. Geophys. 100 $8-43$.

Frank-Kamenetsky A V, Troshichev O A, Burns G B and Papitashvili V O 2001 Variations of the atmospheric electric field in the near-pole region related to the interplanetary magnetic field; J. Geophys. Res. 106 179-190.

Harrison R G 1992 Aerosol charging and radioactivity; PhD Thesis, University of London.

Harrison R G 2005 The global atmospheric electric circuit and climate; Surv. Geophys. 25 441-484.

Harrison R G 2007 Electrical properties of the surface atmospheric air at Eskdalemuir, 1909-1911; Atmos. Res. 84 182-188.

Hõrrak U, Salm J and Tammet H 1999 Classification of natural air ions near the ground; In: Proc. 11th Int. Conf. on Atmospheric Electricity (NASA/CP-1999209261), (ed.) Christian H J, Alabama, 7-11 June 1999, 618-621.

Israel H 1973a Atmospheric Electricity, vol. I, Fundamentals, Conductivity, Ions; Published for the National Science Foundation by the Israel Program for Scientific Translations, ISBN 0706511298.

Israel H 1973b Atmospheric Electricity, vol. II, Fields, Charges and Currents; Published for the National Science Foundation by the Israel Program for Scientific Translations, ISBN 0706511298.

Kamra A K, Deshpande C G and Gopalakrishnan V 1994 Challenge to the assumption of the unitary diurnal variation of atmospheric potential gradient based on observation in the Indian Ocean, Bay of Bengal and Arabian Sea; J. Geophys. Res. 99 21,043-21,050.

Kamra A K and Deshpande C G 1995 Possible secular and land-to-ocean extension of air pollution from measurements of atmospheric electrical conductivity over the Bay of Bengal; J. Geophys. Res. 100 7105-7110.

Kamra A, Murugavel P, Pawar S and Gopalakrishnan V 2001 Background aerosol concentration derived from the atmospheric electric conductivity measurements made over the Indian Ocean during INDOEX; J. Geophys. Res. 106(D22) 28,643-28,651. 
Kasemir H W 1972 Atmospheric electric field measurements in the Arctic and Antarctic; Pure Appl. Geophys. 100 $70-80$.

Leblanc F, Aplin K, Yair Y, Harrison G, Lebreton J P and Blanc M 2008 Planetary atmospheric electricity; Space Sci. Rev. 137 1-532.

Markson R 2007 The global electric circuit intensity, its measurements and variation over the last 50 years; Bull. Am. Meteor. Soc. 88(2) 223-241.

Panneerselvam C, Selvaraj C, Jeeva K, Nair K U, Anilkumar C P and Gurubaran S 2007 Fair weather atmospheric electricity at Antarctica during local summer as observed from Indian station, Maitri; J. Earth Syst. Sci. 116 179-186.

Parkinson W C and Torrenson O W 1931 The diurnal variation the electrical potential of the atmosphere over oceans; Terrest. Magn. Electr. Bull. 8 340-345.

Reddell B D, Benbrook J R, Bering E A, Cleary E N and Few A A 2004 Seasonal variations of atmospheric electricity measured at Amundsen-Scott South Pole station; J. Geophys. Res. 109 A09308, doi: 10.1029/ 2004JA010536.

Roble R G and Tzur I 1986 The global atmospheric electrical circuit; Study in Geophysics - The Earth's electrical Environment (Washington, DC: National Academy Press) 206-231.

Rycroft M J, Israelsson S and Price C 2000 The global atmospheric electric circuit, solar activity and climate change; J. Atmos. Sol.-Terr. Phys. 62 1563-1576.

Rycroft M J 2006 Electrical processes coupling the atmosphere and ionosphere: An overview; J. Atmos. Sol.Terr. Phys. 68 445-456.

Rycroft M J, Harrison R G, Nicoll K A and Mareev E A 2008 An overview of Earth's global electric circuit and atmospheric conductivity; Space Sci. Rev. 137 83-105.

Siingh D, Pawar S D, Gopalakrishnan V and Kamra A K 2005a Measurements of the ion concentrations and conductivity over the Arabian Sea during the ARMEX; J. Geophys. Res. 110 D18207, doi: 10.1029/ 2005JD005765.

Siingh D, Singh R P, Kamra A K, Gupta P N, Singh R, Gopalakrishnan V and Singh A K 2005b Review of electromagnetic coupling between the Earth's atmosphere and the space environment; J. Atmos. Sol.-Terr. Phys. 67 637-658.
Siingh D, Gopalakrishnan V, Singh R P, Kamra A K, Singh S, Pant V, Singh R and Singh A K 2007 The atmospheric global electric circuit: An overview; Atmos. Res. 84 91-110.

Simpson G C 1929 Discussion on the paper by F J W Whipple, "On the association of the diurnal variation of electric potential gradient in fine weather with the distribution of thunderstorms over the globe"; Quart. J. Roy. Met. Soc. 55 13-15.

Singh D K, Singh R P and Kamra A K 2004 The electrical environment of the Earth's atmosphere: A review; Space Sci. Rev. 113 375-408.

Swann W F G 1915 The atmospheric-electric observations on the third cruise of 'Carnegie', 1914; Terr. Magn. Atmos. Electr. 20 13-48.

Tammet H 1995 Size and mobility of atmospheric particles, clusters and ions; Aerosol Sci. 26 459-475.

Tammet H, Israelsson S, Knudsen K and Tuomi T J 1996 Effective area of a horizontal long-wire antenna collecting the atmospheric electric vertical current; J. Geophys. Res. $10129,671-29,678$.

Tinsley B A 2000 Influence of solar wind on the global electric circuit, and inferred effects on cloud microphysics, temperature, and dynamics in the troposphere; Space Sci. Rev. 94 231-258.

Torreson D W, Parkinson W D, Gish O H and Wait G R 1946 Scientific results of curise VII of the 'Carnegie' ocean atmospheric electric results; Publ. Rep. $\mathbf{5 6 8}$ Carnegie Ints., Washington D.C., 1-176.

Whipple F J W and Scrase F J 1936 Point discharge in the electric field of the Earth; Geophys. Mem. 68 1-20.

Williams E R and Satori G 2004 Lightning, thermodynamic and hydrological comparison of the two tropical continental chimneys; J. Atmos. Sol.-Terr. Phys. 66 1213-1231.

Williams E R 2005 Lightning and climate: A review; Atmos. Res. 76 272-287.

Williams E 2007 The global electrical circuit: A review; Proceedings of the 13th International Conference on Atmospheric Electricity (ICAE), 1-4, Beijing, China, August 13-17.

Williams E R 2009 The global electrical circuit: A review; Atmos. Res. 91 140-152.

Wilson C T R 1920 Investigations on lightning discharges and the electric field of thunderstorms; Phil. Trans. A. 221 73-115. 